\title{
Inversion Temperature in the Separation of Isobaric CO Molecules by Thermal Diffusion
}

\author{
By A. E. de Vries and A. Haring \\ F. O. M. Laboratorium voor Massascheiding, Amsterdam/O. \\ (Z. Naturforschg. 19 a, 225-230 [1964] ; eingegangen am 19. Oktober 1963)
}

\begin{abstract}
In specially constructed thermal diffusion columns separations between the isotopic mixtures ${ }^{12} \mathrm{C}^{18} \mathrm{O} /{ }^{12} \mathrm{C}^{16} \mathrm{O}$ and ${ }^{14} \mathrm{C}^{16} \mathrm{O} /{ }^{12} \mathrm{C}^{16} \mathrm{O}$ were measured at average temperatures ranging from $T=260{ }^{\circ} \mathrm{K}$ to $T=465{ }^{\circ} \mathrm{K}$. At temperatures above $320{ }^{\circ} \mathrm{K}{ }^{14} \mathrm{C}^{16} \mathrm{O}$ concentrates more strongly in the cold region than ${ }^{12} \mathrm{C}^{18} \mathrm{O}$. Below this temperature the opposite effect is taking place: the thermal diffusion factor $\alpha\left({ }^{12} \mathrm{C}^{18} \mathrm{O} /{ }^{12} \mathrm{C}^{16} \mathrm{O}\right)$ is greater than $\alpha^{\prime}\left({ }^{14} \mathrm{C}^{16} \mathrm{O} /{ }^{12} \mathrm{C}^{16} \mathrm{O}\right)$. All separations were carried out at temperatures for which the heavier molecule concentrates in the cold region.
\end{abstract}

The fact that a mixture of isotopic-isobaric molecules has a finite thermal diffusion factor has not yet been explained satisfactorily although a dimensional treatment ${ }^{1}$ shows that the influence of the moment of inertia may be as important as the mass difference. Although the thermal diffusion factor for these mixtures is very small so that a possible temperature dependence is hard to measure, it seemed worth-while to investigate this dependence in a mixture of molecules where quantumeffects cannot play a role. We chose $\mathrm{CO}$ for which the ratio of the thermal diffusion factors

$$
\alpha^{\prime}\left({ }^{14} \mathrm{C}^{16} \mathrm{O} /{ }^{12} \mathrm{C}^{16} \mathrm{O}\right) \text { and } \alpha\left({ }^{12} \mathrm{C}^{18} \mathrm{O} /{ }^{12} \mathrm{C}^{16} \mathrm{O}\right)
$$

at one average temperature $\left(440{ }^{\circ} \mathrm{K}\right)$ was determined some time ago ${ }^{2}$.

In the case of a temperature dependence measurement it was necessary to get as big a separation as possible so that the use of a thermal diffusion column was a conditio sine qua non. The disadvantage of a column is the assignment of an average temperature. Measurements therefore were done at a few temperatures, lying well outside each others range.

\section{Experimental}

To be able to get a reasonably low temperature, we constructed a number of "Dewar-Columns" which were cooled with methylalcohol by means of a Lauda ultracryostat UK 80 with which we could reach a cold outerwall of $-70^{\circ} \mathrm{C}$. The columns were conical wire columns with a length of $140 \mathrm{~cm}$ and a diameter of 9.0 to $9.8 \mathrm{~mm}$. Six columns were made of which two times

1 J. Schirdewahn, A. Klemm, and L. Waldmann, Z. Naturforschg. 16 a, 133 [1961].

2 A. E. de Vries, A. Haring, and W. Slots, Physica 22, 247 [1956].

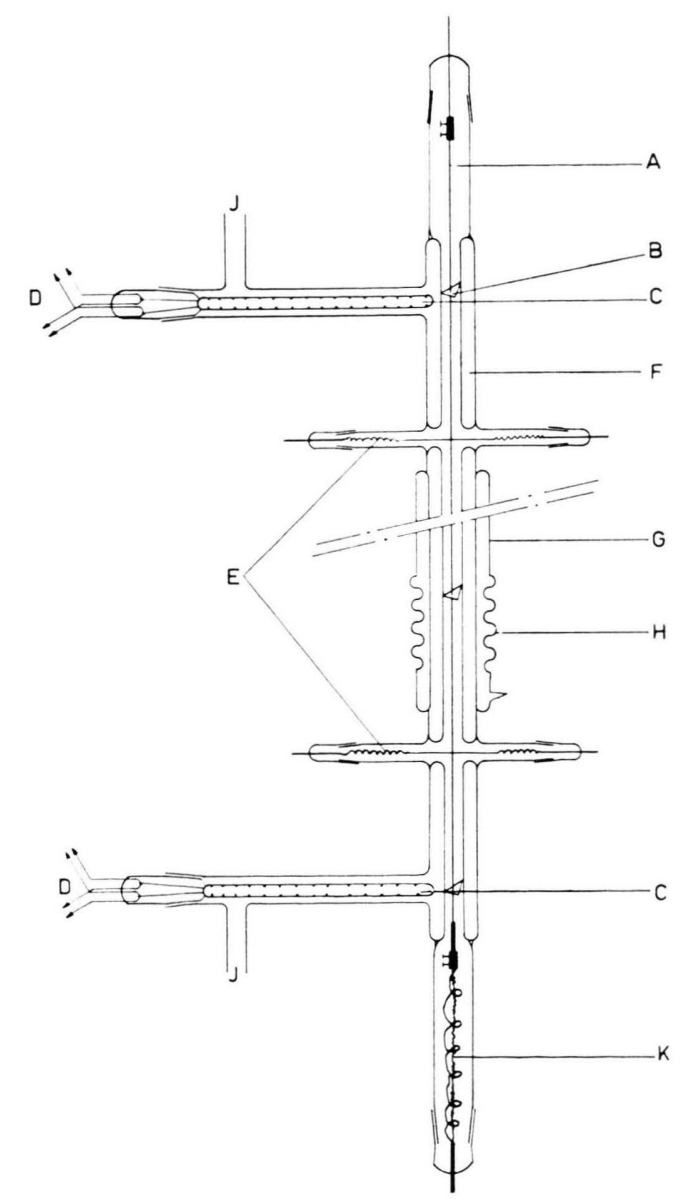

Fig. 1. Dewar column for separations at low temperatures. A Platinum $20 \%$ Iridium wire with diameter of $0.5 \mathrm{~mm}$. B Spacers for centering wire. C Platinum resistance. D Connections to battery and compensator for measuring resistance. E Thermocouples. F Cooling mantle. G Evacuated silverplated glasstube. H Thin expansion spring of silverplated glass to compensate tension caused by cooling. J Cooling liquid. K Stainless steal spring to keep wire stretched. 


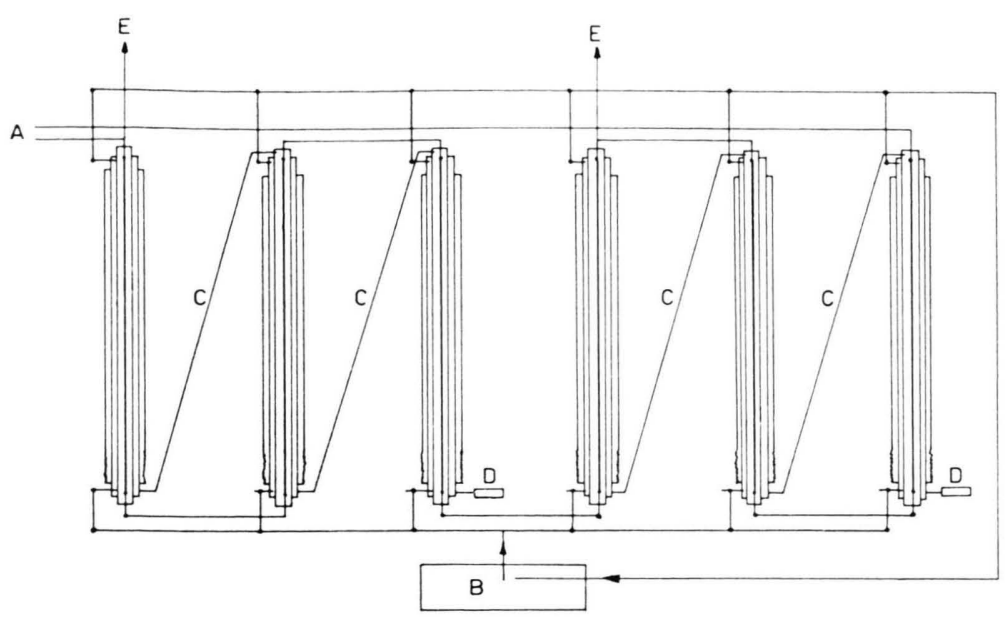

Fig. 2. Schematic diagram of the thermal diffusion columns. A Electrical supply. B Cryostat for cooling. C Pyrex capillary tube. D Heating for swinging the gas up and down through the capillary tubes. The heating is switched on and off every 10 minutes. The volume of the gas in this bulb is $80 \mathrm{ml}$. E Reservoir of $25000 \mathrm{ml}$.

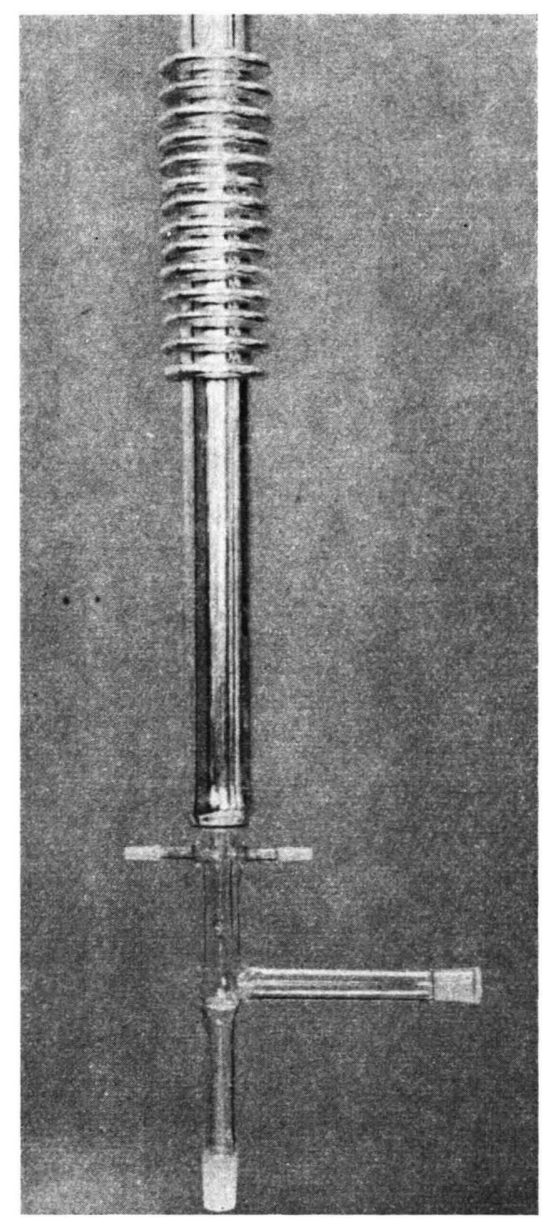

Fig. 3. Bottom part of thermal diffusion column with evacuated silver-plated outerwall.

three were put in series by means of a "Schaukel" (swingseparator). Thus two experiments could be done at the same time in two columns with a length of $420 \mathrm{~cm}$ each. See Figs. 1 and 2 .

The temperature of the cold wall was measured by a platinum resistance thermometer with an accuracy of about one degree. The temperature of the $0.5 \mathrm{~mm}$ thick wire was measured by means of platinum-platinumrhodium thermocouples at the top and bottom of each column. The temperature over the whole unit was constant within $10^{\circ} \mathrm{C}$. These columns were used for the experiments at $\bar{T}=260{ }^{\circ} \mathrm{K}$ and $T=350{ }^{\circ} \mathrm{K}$. The separations at $320^{\circ} \mathrm{K}, 440{ }^{\circ} \mathrm{K}$ and $465^{\circ} \mathrm{K}$ were done in normal columns with the same diameters as the Dewar columns. The columns were filled with $\mathrm{CO}$ to which some ${ }^{14} \mathrm{CO}$ was added. The ${ }^{14} \mathrm{CO}$ was bought from A mersham, England in the form of $\mathrm{BaCO}_{3}$, converted to $\mathrm{CO}_{2}$ by means of perchloric acid and reduced to $\mathrm{CO}$ by passing it over a zincasbestos mixture heated to $380{ }^{\circ} \mathrm{C}$. The natural $\mathrm{CO}$ was made in the same way. The $\mathrm{CO}$ with which the column was filled ultimately contained less than $0.5 \%$ of other gases. During a run some $\mathrm{CO}_{2}$ was formed which was con- densed in liquid air before analysis. The amount of $\mathrm{CO}_{2}$ never exceeded $2 \%$. Analyses for ${ }^{18} \mathrm{O}$ were done on an $\mathrm{Atlas} \mathrm{CH}_{4}$ mass spectrometer. The ${ }^{14} \mathrm{C}$ analyses were made by converting the $\mathrm{CO}$ to $\mathrm{BaCO}_{3}$ and measuring "infinitely thick" samples on an end-window Geiger-Müller counter 18506 and counting unit PW 4032 from $\mathrm{P}$ hilip s.

\section{Results}

The results are given in Table 1 together with 6 measurements which had been measured before ${ }^{2}$. The separationfactor $q$ for the ${ }^{12} \mathrm{C}^{18} \mathrm{O}$ is given by the well known expression

$$
q=\frac{\left({ }^{12} \mathrm{C}^{18} \mathrm{O} /{ }^{12} \mathrm{C}^{16} \mathrm{O}\right) \text { bottom }}{\left({ }^{12} \mathrm{C}^{18} \mathrm{O} /{ }^{12} \mathrm{C}^{16} \mathrm{O}\right) \text { top }}=\frac{(30) /(28)_{\text {bottom }}}{(30) /(28)_{\text {top }}} .
$$

The separationfactor $q^{\prime}$ for the ${ }^{14} \mathrm{C}^{16} \mathrm{O}$ is simply the ratio of the activities of the two samples at the bottom and the top, corrected for background and dead time. The counting rate was $500-2000$ counts per minute. 
The average temperature in the column was calculated according to

$$
\bar{T}=T_{\mathrm{c}}+0.25\left(T_{\mathrm{h}}-T_{\mathrm{c}}\right) .
$$

A plus sign in the difference between the separations always means that the separation between ${ }^{12} \mathrm{C}^{16} \mathrm{O}$ and ${ }^{14} \mathrm{C}^{16} \mathrm{O}$ is bigger than between ${ }^{12} \mathrm{C}^{16} \mathrm{O}$ and ${ }^{12} \mathrm{C}^{18} \mathrm{O}$. The sign is quite arbitrary because the usual

\begin{tabular}{|c|c|c|c|c|c|}
\hline 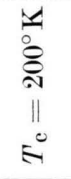 & 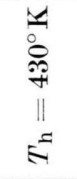 & 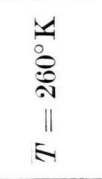 & 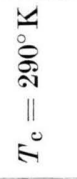 & $\begin{array}{l}\frac{1}{1} \\
0 \\
7 \\
\| 1 \\
E \\
E\end{array}$ & 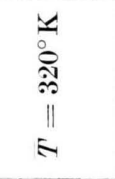 \\
\hline \multirow{3}{*}{$\begin{array}{c}q \\
1.58 \\
1.43 \\
1.62 \\
1.60 \\
1.78 \\
1.60 \\
1.76 \\
1.58 \\
1.75\end{array}$} & \multirow{3}{*}{$\begin{array}{c}q^{\prime} \\
1.24 \\
1.24 \\
1.41 \\
1.43 \\
1.58 \\
1.45 \\
1.59 \\
1.36 \\
1.49\end{array}$} & \multirow{3}{*}{$\begin{array}{c}\frac{\Delta \alpha}{\alpha} \\
-0.53 \\
-0.40 \\
-0.29 \\
-0.24 \\
-0.21 \\
-0.21 \\
-0.18 \\
-0.33 \\
-0.29\end{array}$} & $\begin{array}{c}q \\
1.58 \\
2.01 \\
2.20 \\
2.07\end{array}$ & $\begin{array}{l}q^{\prime} \\
1.63 \\
2.0 \\
2.07 \\
2.11\end{array}$ & $\begin{aligned} & \frac{\Delta \alpha}{\alpha} \\
+ & 0.070 \\
- & 0.01 \\
- & 0.076 \\
+ & 0.025\end{aligned}$ \\
\hline & & & 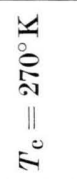 & 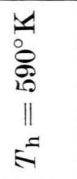 & 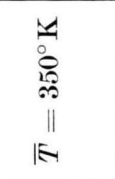 \\
\hline & & & $q$ & $q^{\prime}$ & $\frac{\Delta \alpha}{\alpha}$ \\
\hline 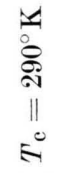 & 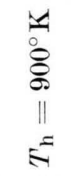 & 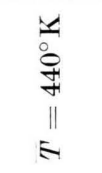 & $\begin{array}{l}2.90 \\
2.89 \\
3.67 \\
3.67 \\
3.64\end{array}$ & $\begin{array}{l}3.08 \\
3.13 \\
4.03 \\
3.94 \\
4.05\end{array}$ & $\begin{array}{r}+0.056 \\
+0.075 \\
+0.072 \\
+0.055 \\
+0.083\end{array}$ \\
\hline $\begin{array}{c}q \\
5.37 \\
4.62 \\
5.70\end{array}$ & $\begin{array}{l}q^{\prime} \\
6.55 \\
5.99 \\
7.61\end{array}$ & $\begin{array}{r}\frac{\Delta \alpha}{\alpha} \\
+0.12 \\
+0.17 \\
+0.17\end{array}$ & $\begin{array}{l}\frac{1}{0} \\
\stackrel{8}{*} \\
\| \\
\| \\
0\end{array}$ & 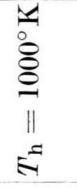 & 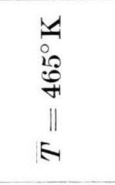 \\
\hline $\begin{array}{l}5.87 \\
7.39\end{array}$ & $\begin{array}{l}7.77 \\
8.76\end{array}$ & $\begin{array}{l}+0.16 \\
+0.15\end{array}$ & $q$ & $q^{\prime}$ & $\frac{\Delta \alpha}{\alpha}$ \\
\hline 9.03 & 13.3 & +0.18 & 12.1 & 17.0 & +0.136 \\
\hline 7.85 & $\begin{array}{l}9.87 \\
5.99\end{array}$ & $\begin{array}{r}+0.11 \\
+018\end{array}$ & 11.8 & 19.6 & +0.205 \\
\hline $\begin{array}{l}4.57 \\
6.69\end{array}$ & $\begin{array}{l}5.99 \\
8.08\end{array}$ & $\begin{array}{r}+0.18 \\
+0.10\end{array}$ & 13.0 & 16.3 & $\begin{array}{r}+0.086 \\
+0.13\end{array}$ \\
\hline & & & $\begin{array}{l}17.4 \\
16.6 \\
13.4\end{array}$ & $\begin{array}{l}27.0 \\
30.0 \\
21.4\end{array}$ & $\begin{array}{r}+0.153 \\
+0.210 \\
+0.177\end{array}$ \\
\hline
\end{tabular}

Table 1. Separationfactor and fractional differences in the thermal diffusion factors of isotopic CO-mixtures at different temperatures. $T_{\mathrm{c}}=$ Temperature cold wall in ${ }^{\circ} \mathrm{K}, T_{\mathrm{h}}=\mathrm{Tem}$ perature hot wire in ${ }^{\circ} \mathrm{K}, \bar{T}=$ Average temperature in ${ }^{\circ} \mathrm{K}$, $q=q\left({ }^{12} \mathrm{C}^{18} \mathrm{O} /{ }^{12} \mathrm{C}^{16} \mathrm{O}\right), \quad q^{\prime}=q^{\prime}\left({ }^{14} \mathrm{C}^{16} \mathrm{O} /{ }^{12} \mathrm{C}^{16} \mathrm{O}\right)$,

$$
\Delta \alpha / \alpha=\left(\ln q^{\prime}-\ln q\right) / \ln q \text {. }
$$

3 A. N. Davenport and E. R. S. Winter, Trans. Faraday Soc. 47, 1160 [1951]. convention for thermal diffusion factors makes only use of the molecular masses. We have adopted the rule given above because up to now in most experiments the molecule with the smaller difference in atomic masses behaved like the heavier one ${ }^{1,2}$, so that in this sense the negative sign at low temperatures is an exception.

The separationfactor in a column is given by $q=e^{k \alpha}$ in which $\alpha$ is the thermal diffusion factor defined by $\operatorname{grad} c=\alpha c_{1} c_{2} \operatorname{grad} \ln T$ for a convection-free process and $k$ is dependent on the properties of the gas and the column. In our case the enrichments of the pairs ${ }^{14} \mathrm{C}^{16} \mathrm{O} /{ }^{12} \mathrm{C}^{16} \mathrm{O}$ and ${ }^{12} \mathrm{C}^{18} \mathrm{O} /$ ${ }^{12} \mathrm{C}^{16} \mathrm{O}$ are measured simultaneously in the same ternary mixture in the same column. Because of the low concentrations of two of the three components the mixture behaves as a quasi double-binary mixture and we find for the separationfactors

$$
q^{\prime}\left({ }^{14} \mathrm{C}^{16} \mathrm{O} /{ }^{12} \mathrm{C}^{16} \mathrm{O}\right) \text { and } q\left({ }^{12} \mathrm{C}^{18} \mathrm{O} /{ }^{12} \mathrm{C}^{16} \mathrm{O}\right)
$$

of the two mixtures $q=e^{k \alpha}$ and $q^{\prime}=e^{k \alpha^{\prime}}$. This gives

$$
\begin{aligned}
& \ln q^{\prime}-\ln q=k\left(\alpha^{\prime}-\alpha\right), \\
& \frac{\Delta \alpha}{\alpha}=\frac{\alpha^{\prime}-\alpha}{\alpha}=\frac{\ln q^{\prime}-\ln q}{\ln q} .
\end{aligned}
$$

The thermal diffusion factor $\alpha\left({ }^{12} \mathrm{C}^{18} \mathrm{O} /{ }^{12} \mathrm{C}^{16} \mathrm{O}\right)$ was taken to be 0.015 at $440{ }^{\circ} \mathrm{K}$. This is about twice the value found for $\alpha\left({ }^{13} \mathrm{C}^{16} \mathrm{O} /{ }^{12} \mathrm{C}^{16} \mathrm{O}\right)^{3}$ and is in agreement with a potential well $\varepsilon / k=100{ }^{\circ} \mathrm{K}$ as calculated from viscosity and second virial coefficients ${ }^{4 a}$. From the known value of $\varepsilon / k$ the thermal diffusion factor at other temperatures was calculated.

The temperature dependence differs a little for a Lennard-Jones potential and modified Buckingham potentials with different steepness parameters, but not more than a few percent. The values of the thermal diffusion factors for the different models at different temperatures divided by the value at $440{ }^{\circ} \mathrm{K}$ as calculated from the tables given in Hirschfelder c. s. are given in Table 2 . In the last column the value is given which was used in our computations.

Average experimental values of $\Delta \alpha / \alpha$ and $10^{3} \Delta \alpha$ at the different temperatures are given in Table 3 . The assumed value of $\alpha\left(440^{\circ} \mathrm{K}\right)=0.015$ is used only in the calculation of $10^{3} \Delta \alpha$. See also Fig. 4 .

4 J. O. Hirschfelder, C. F. Curtiss, and R. B. Bird, Molecular Theory of Gases and Liquids, John Wiley \& Sons Inc., N. Y., Chapman and Hall Ltd., London 1954, pages: a) 1111 , b) 1131 , c) 1175 . 


\begin{tabular}{|c|c|c|c|c|}
\hline$T$ in ${ }^{\circ} \mathrm{K}$ & \multicolumn{3}{|c|}{$\alpha(T) / \alpha(440)$} \\
& L. J.4b & \multicolumn{2}{|c|}{$\begin{array}{c}\text { Buckingham } 4 \mathrm{c} \\
\text { with }\end{array}$} & $\begin{array}{c}\text { value used } \\
\text { in our } \\
\text { calculations }\end{array}$ \\
\cline { 2 - 4 } & & $s=12$ & $s=15$ & \\
\hline 260 & 0.73 & 0.69 & 0.74 & 0.72 \\
320 & 0.85 & 0.84 & 0.86 & 0.85 \\
350 & 0.90 & 0.89 & 0.91 & 0.90 \\
440 & 1.00 & 1.00 & 1.00 & 1.00 \\
465 & 1.02 & 1.02 & 1.02 & 1.02 \\
\hline
\end{tabular}

Table 2. Temperature dependence of the thermal diffusion factor of $\mathrm{CO}$ for different potentials, $\varepsilon / k=100^{\circ} \mathrm{K}$.

\begin{tabular}{|c|c|c|}
\hline$T$ & $\Delta \alpha / \alpha$ & $10^{3} \Delta \alpha$ \\
\hline $\begin{array}{l}260 \\
320 \\
350 \\
440 \\
465\end{array}$ & $\begin{array}{l}-0.30 \pm 0.11 \\
+0.01 \pm 0.06 \\
+0.06 \pm 0.02 \\
+0.15 \pm 0.03 \\
+0.15 \pm 0.05\end{array}$ & $\begin{array}{l}-3.2 \pm 1.1 \\
+0.1 \pm 0.8 \\
+0.8 \pm 0.3 \\
+2.2 \pm 0.4 \\
+2.3 \pm 0.8\end{array}$ \\
\hline
\end{tabular}

Table 3. Fractional and absolute differences in the thermal diffusion factors of the mixtures ${ }^{14} \mathrm{C}^{16} \mathrm{O} /{ }^{12} \mathrm{C}^{16} \mathrm{O}$ and ${ }^{12} \mathrm{C}^{18} \mathrm{O} /{ }^{12} \mathrm{C}^{16} \mathrm{O}$ at different temperatures.

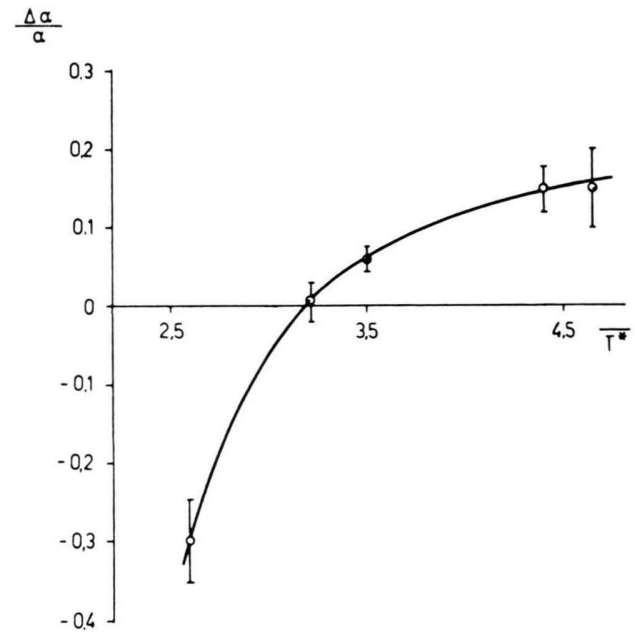

Fig. 4. Experimental values of $\Delta \alpha / \alpha$ at different reduced temperatures. $\quad \downarrow \alpha=\alpha^{\prime}-\alpha, \quad \alpha=\alpha\left({ }^{12} \mathrm{C}^{18} \mathrm{O} /{ }^{12} \mathrm{C}^{16} \mathrm{O}\right)$, $\alpha^{\prime}=\alpha^{\prime}\left({ }^{14} \mathrm{C}^{16} \mathrm{O} /{ }^{12} \mathrm{C}^{16} \mathrm{O}\right), T^{*}=k T / \varepsilon, \varepsilon / k=100$.

\section{Discussion}

\section{a) The depth of the potential well $\varepsilon / k$ for $\mathrm{CO}$}

In discussing our results the assignment of the potential well $\varepsilon / k$ presents some difficulties. As mentioned before a value of about $100^{\circ} \mathrm{K}$ is usually

* In the book of Hirschfelder c. s. ${ }^{4}$ the symbol $\alpha$ is used for the so-called steepness-parameter. In order to avoid confusion with the thermal diffusion factor, we use $s$. - accepted (Hirschfelder ${ }^{4 a}$ ). This value is found from viscosity as well as from second virial coefficient measurements. AMdur and Shuler ${ }^{5}$, however, recently measured the self-diffusion coefficients of CO by means of ${ }^{14} \mathrm{CO}$ between $195{ }^{\circ} \mathrm{K}$ and $373{ }^{\circ} \mathrm{K}$ and calculated from their results $\varepsilon / k=32.8^{\circ} \mathrm{K}$. Although one might expect thermal diffusion to behave similar to diffusion in this respect, measurements of Davenport and $W_{\text {Inter }}{ }^{3}$ exclude this low value of $\varepsilon / k$ for thermal diffusion. The temperature dependence of $\alpha$ between $300{ }^{\circ} \mathrm{K}$ and $400{ }^{\circ} \mathrm{K}$ is far too big for a $\varepsilon / k$ of about $30^{\circ} \mathrm{K}$ and actually is in good agreement with a value of about $100^{\circ} \mathrm{K}$. We will therefore base our discussion on this value.

\section{b) Qualitative behaviour of the potential energy curve}

The reduced temperatures $k T / \varepsilon$ at which our measurements were taken, are then

$T^{*}=2.6, \quad T^{*}=3.2, \quad T^{*}=3.5, \quad T^{*}=4.4, \quad T^{*}=4.65$.

Below $T^{*}=3.2$ the thermal diffusion factor

$$
\alpha\left({ }^{12} \mathrm{C}^{18} \mathrm{O} /{ }^{12} \mathrm{C}^{16} \mathrm{O}\right)>\alpha{ }^{\prime}\left({ }^{14} \mathrm{C}^{16} \mathrm{O} /{ }^{12} \mathrm{C}^{16} \mathrm{O}\right),
$$

while above $T^{*}=3.2$, we find $\alpha<\alpha^{\prime}$.

It needs emphasizing that at all temperatures the thermal diffusion factor between isotopic molecules with a different mass is positive, i. e. the molecule with the heavier mass concentrates always in the cold region. A change in this sign could be expected only at temperatures below $\sim 120^{\circ} \mathrm{K}\left(T^{*}<1.2\right.$, see paragraph $\mathrm{c}$ of this discussion). It is noteworthy that the temperature at which $\alpha=\alpha^{\prime}$ lies very close to the Boyle temperature $T_{\mathrm{B}}$ at which the second virialcoefficient is 0 . It is known that above this temperature repulsive forces dominate while at temperatures below $T_{\mathrm{B}}$ the attractive forces are of more importance. For molecules which interact according to a Lennard-Jones potential the reduced Boyle temperature $T_{\mathrm{B}}{ }^{*}=3.4$. One is tempted therefore to explain the experimental behaviour of the different CO-molecules by two different potential energy curves which have the appearance as given in Fig. 5:

$$
\begin{gathered}
\varepsilon^{\prime}\left({ }^{14} \mathrm{C}^{16} \mathrm{O}\right)>\varepsilon\left({ }^{12} \mathrm{C}^{18} \mathrm{O}\right), \\
\sigma / r_{\mathrm{m}}\left({ }^{14} \mathrm{C}^{16} \mathrm{O}\right)>\sigma / r_{\mathrm{m}}\left({ }^{12} \mathrm{C}^{18} \mathrm{O}\right) .
\end{gathered}
$$

The steepness $s$ is a single-valued function of $\sigma / r_{\mathrm{m}}$. See ref. 4 page 34 table $1.3-1$.

5 I. Amdur and L. M. Shuler, J. Chem. Phys. 38, 188 [1963]. 
At low temperatures the influence of the potential well $\varepsilon$ is more pronounced and because $T^{*}=k T / \varepsilon$ we get $T^{*}>T^{\prime *}$ and therefore $\alpha>\alpha^{\prime}$, while at higher temperatures, where the steepness $s$ is dominant, $\alpha<\alpha^{\prime}$. Inspection of the table VII-D of HirchfeLDER ${ }^{4 \mathrm{c}}$ shows that the modified Buckingham potential can explain the experimental behaviour qualitatively. It is apparent, however, that only big differences in $\varepsilon$ and $s$ might give values which coincide with the observed separations.

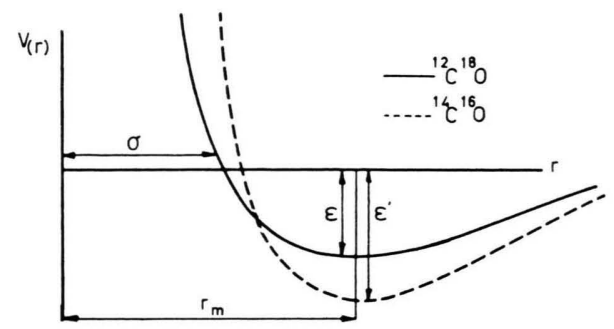

Fig. 5. Qualitative behaviour of potential energy curve for ${ }^{12} \mathrm{C}^{18} \mathrm{O}$ and ${ }^{14} \mathrm{C}^{16} \mathrm{O}$. $\sigma=$ zero-energy diameter of ${ }^{12} \mathrm{C}^{18} \mathrm{O}, r_{\mathrm{m}}=$ distance for which the potential energy is a minimum, $\varepsilon$ and $\varepsilon^{\prime}=$ depths of potential wells for ${ }^{12} \mathrm{C}^{18} \mathrm{O}$ and ${ }^{14} \mathrm{C}^{16} \mathrm{O}$.

In Table 4 values of $10^{4} \alpha$ and $10^{4} \alpha^{\prime}$, calculated from Hirschfelder's Table VII-D, are given for the isobaric molecules. From the values, in which we took $s=12$ and $s=15$ respectively and $\varepsilon^{\prime} / \varepsilon=1.37$ we calculated $\Delta \alpha / \alpha$. A comparison with experimental $\Delta \alpha / \alpha$ values shows that the latter ones are several times bigger than the calculated ones. The values $s=12$ and $s=15$ were chosen because they are the two extreme values given in the table. In order to get $\Delta \alpha / \alpha=0$ at $320^{\circ} \mathrm{K}$, one then has to take $\varepsilon^{\prime} / \varepsilon=1.37$. The two values of $\varepsilon / k$ and $\varepsilon^{\prime} / k$ are then $86.5^{\circ} \mathrm{K}$ and $118.5^{\circ} \mathrm{K}$ respectively, both values be-

$260^{\circ} \mathrm{K} 320^{\circ} \mathrm{K} 350^{\circ} \mathrm{K} 440^{\circ} \mathrm{K} 465^{\circ} \mathrm{K}$

\begin{tabular}{|l|l|l|l|l|l|}
$10^{4} \alpha^{\prime}\left({ }^{14} \mathrm{C}^{16} \mathrm{O} /{ }^{12} \mathrm{C}^{16} \mathrm{O}\right)$ & 107 & 123 & 130 & 142 & 144 \\
\hline
\end{tabular}

\begin{tabular}{|l|l|l|l|l|r|}
$10^{4} \alpha\left({ }^{12} \mathrm{C}^{18} \mathrm{O} /{ }^{12} \mathrm{C}^{16} \mathrm{O}\right)$ & 102 & 123 & 132 & 151 & 155 \\
\hline
\end{tabular}

\begin{tabular}{l|ll|l}
$\frac{\Delta \alpha}{\alpha}$ (calculated) & -0.05 & 0 & $+0.02+0.06+0.11$
\end{tabular}

$\frac{\Delta \alpha}{\alpha}$ (measured) $\quad-0.30 \quad 0 \quad+0.06+0.15+0.15$

Table 4. Experimental and calculated values $\Delta a / \alpha$ for isotopic $\mathrm{CO}$-molecules with the following parameters:

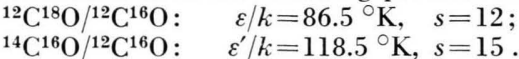

${ }^{6}$ E. W. Becker and W. Beyrich, J. Phys. Chem. 56, 911 [1952].

7 G. Ember, J. R. Ferron, and K. Wohl, J. Chem. Phys. 37, 891 [1962]. ing close to the value found from the depth of the potential well from viscosity and second virial coefficient, namely $100^{\circ} \mathrm{K}$.

It is clear that even bigger differences are needed between the potential wells $\varepsilon$ and $\varepsilon^{\prime}$ and the steepnessparameters $s$ and $s^{\prime}$ to explain the experimental results.

\section{c) Differences in $\varepsilon / k$ for isotopic molecules}

It is distressing that some other observations point to differences in potential parameters as large as or even larger than the differences found in our case: BECKER and BEYRICH ${ }^{6}$ measured the inversion temperatures for thermal diffusion of symmetric and asymmetric $\mathrm{CO}_{2}$-molecules and found $300{ }^{\circ} \mathrm{K}$ and $378{ }^{\circ} \mathrm{K}$ respectively, the ratio being 1.39 .

The experimental value as found from viscosity and second virial coefficients, is $\varepsilon / k \cong 200{ }^{\circ} \mathrm{K}^{4 \mathrm{a}}$ so $T^{*}$ (inversion) $=1.5-1.9$. The calculated inversion temperature for any reasonable potential however should lie between $T^{*}=0.8$ and 1.2 (the lowest reduced inversion temperature exists for a modified Buckingham potential with a steepness parameter $s=14$. For higher steepness the thermal diffusion factor does not change sign at any temperature).

Even worse is that Ember et al. ${ }^{7}$ recently calculated from self-diffusion coefficients of $\mathrm{CO}_{2}$ $\varepsilon / k=871{ }^{\circ} \mathrm{K}$.

The results of Amdur and Shuler ${ }^{5}$ in which $\varepsilon / k$ for CO from self-diffusion is a factor of about three lower than is found from viscosity and second virial coefficients have been mentioned already.

\section{d) Inversion temperature for viscosity and second virial coefficients}

In connection with the experiments described in this paper, it may be mentioned that also for the viscosity and the second virial coefficient inversion temperatures similar to the ones we have found, exist. Coremans ${ }^{8}$ measured the viscosity of different hydrogenmolecules and found that the viscosity of $\mathrm{HD}$ at a reduced temperature of $T^{*}=0.8$ is almost the same as that of $\mathrm{D}_{2}$ but at $T^{*}=2.0$ is equal to the viscosity of $\mathrm{H}_{2}$. He also calculated the viscosity of a hypothetical hydrogenmolecule with a mass of 3

8 J. M. J. Coremans, De viscositeitscoëfficiënt van gassen bij lage temperaturen, thesis Leiden 1960 , page 45. 
and found that at $T^{*}=1.4$ the viscosities of this hypothetical molecule and the real $\mathrm{HD}$ are equal. Below this temperature HD has a lower viscosity and above $T^{*}=1.4$ it has a higher viscosity than the spherically symmetrical hydrogenmolecule with mass 3 .

$\mathrm{KNAAP}^{9}$ made measurements of second virial coefficients of hydrogen molecules and found the same behaviour in which at about $T^{*}=0.6\left(T=20^{\circ} \mathrm{K}\right)$ the value for the hypothetical spherically symmetrical $\mathrm{HD}$ and the experimental value are equal. Although we want to mention these pecularities one should not forget that in these cases the influence of quantumeffects is very pronounced.

\section{e) Conclusion}

It has been pointed out some time ago by Mason and RICE ${ }^{10}$ that for nonspherical molecules the same set of parameters cannot be used for equilibrium and transport properties. The given examples of Amdur c.s. and Ember c.s. show that even for the

9 H. F. P. KnaA, The Hydrogen Isotopes in the Gaseous and Liquid States, thesis Leiden 1962. diffusion and the viscosity, both transport properties, one cannot find a single set of parameters. In viscosity the collision integral $\Omega^{2,2}$ is important while for diffusion $\Omega^{1,1}$ is determining. Though this may be of importance, it is shown by the results in this paper that even for the same transport property one set of parameters cannot explain the behaviour over a relatively small temperature range. The question, if this is due to inelastic collisions or to the fact that the molecules are asymmetric, remains unanswered.

\section{Acknowledgments}

We are indebted to Professor Kistemaker for his stimulating interest. It is a pleasure to thank Mr. J. VAN $W_{E L}$ for the construction of the columns. We are grateful to Mrs. I. Balster for the ${ }^{14} \mathrm{C}$ measurements and to Mr. J. van Roon for mass spectrometric analyses. This work is part of the research program of the Foundation for Fundamental Research on Matter (F.O.M.) and is made possible by financial support of the Foundation for Pure Scientific Research (Z.W.O.).

${ }^{10}$ E. A. MAson and W. E. Rice, J. Chem. Phys. 22, 843 [1954]. 